\title{
Insecticide substitutes for DDT to control mosquitoes may be causes of several diseases
}

\author{
Md. Mahbubar Rahman
}

Received: 8 March 2012 / Accepted: 27 August 2012 /Published online: 6 September 2012

(C) The Author(s) 2012. This article is published with open access at Springerlink.com

\begin{abstract}
Malaria continues to be a public health problem in Bangladesh, despite efforts in the 1960s to eradicate the vectors through the use of DDT. At one point, eradication of malaria was acclaimed but later on it reappeared. The use of DDT is no more legally allowed in Bangladesh, which has been officially replaced by a number organophosphates and/ or synthetic pyrethroids and their combinations in addition to the integrated vector management (IVM) package. IVM being a community approach is still to go a long way to be mass popular. Adulticides, larvicides, residual sprays, mosquito coil, insecticide-impregnated curtain, aerosol, etc. still serve as the major weapons of mosquito control. Thus, mosquito control still mostly depends on chemical insecticides. Although the use of DDT is banned in Bangladesh, there are reports on its illegal use in different forms. Moreover, there is tons of leftover DDT in Bangladesh, which is likely to cause several diseases. As per one report, about 500 MTs of DDT stockpiles are lying in the Medical Sub-Depots at Chittagong for over a period of 26 years. DDT is a persistent organic pollutant pesticide, which can cause diseases like cancer, endocrine disorder, disruption of immune system, embryonic abnormality, reproductive disorder, etc. Other chemical insecticides, which are replacing DDT, are also not free of hazardous impacts. IVM thus appears to be a wise approach requiring concerted efforts for the management of mosquito to control malaria. Such an IVM comprises use of Bacillus thuringiensis Berliner var. israelensis, methoprene, biocontrol agents, cleaning of breeding sites, pyrethroid-impregnated curtain, etc. Therefore, a wise effort should be adopted to completely
\end{abstract}

Responsible editor: Philippe Garrigues

M. M. Rahman ( $\square)$

Department of Entomology, Bangabandhu Sheikh Mujibur

Rahman Agricultural University (BSMRAU),

Gazipur, Bangladesh

e-mail: drmahbubarr@gmail.com stop the use of DDT, eliminate its stockpiles wherever they are in Bangladesh and to popularise the IVM, not the chemicals-based alternatives throughout the country.

Keywords Persistent organic pollutant - DDT · Mosquito coil $\cdot$ Aerosol $\cdot$ Integrated vector management

\section{Introduction}

Malaria caused by Plasmodium vivax, Plasmodium ovale, Plasmodium malariae and Plasmodium falciparum still is a serious threat in many parts of Bangladesh (Banglapedia 2006). These are transmitted by seven species of mosquitoes. Among them, Anopheles dirus, Anopheles minimus, Anopheles philippinensis and Anopheles sundaicus are the most important species. A. dirus is a wild species found both outdoors and indoors, in hilly forested and foothill areas. $A$. minimus, a primary vector occurring in hilly forested and foothill areas was eliminated through Malaria Eradication Program (MEP) using DDT but has recently reappeared. $A$. philippinensis occurring in flood plain deltaic region also eliminated through MEP is scarcely found now, and A. sundaicus occurring in coastal areas was virtually eliminated through MEP but has recently reappeared. Anopheles annularis usually found in large numbers is an important vector in some places. Anopheles aconitus although not common is a secondary vector in some places, and Anopheles vagus fairly common all over Bangladesh has been recently incriminated as vector. Besides, 79 culicine species have been recorded including Culex quinquefasciatus, which is a vector of filariasis, and Aedes aegypti and Aedes albopictus are suspected as vectors of dengue. DDT because of its health hazardous effects has been banned in 1998 in Bangladesh in compliance with the Stockholm Convention (Rahman 2007), and a number of chemicals in different forms are now used as substitutes 
for DDT. Now the question is: Are these chemical substitutes free of any health hazardous effects? This article provides answers to this question.

\section{Materials and methods}

Available literature has been reviewed to answer the abovementioned question. A visit to the four Medical Sub-Depots (MSDs) at Agrabad, Chittagong to physically verify the recent status of the DDT stockpiles has been undertaken. The author recently carried out a sample market survey and collected information on the substitutes for DDT available and sold in Bangladesh. The information thus collected and reviewed has been compiled into this article.

\section{Results and discussion}

\section{Malaria situation in Bangladesh}

MEP was successfully carried out with residual spray of DDT supplied by WHO during 1960-1977 (eradication era) resulting in near eradication of malaria/mosquito in 1977 (Fig. 1). The use of DDT was continued for mosquito control during 19711992 (control phase) with DDT produced inside the country along with donor-supplied DDT. Subsequently, the Revised Malaria Control Strategy (1993-2002) was adopted (WHO 2009) that included restricted use of DDT and other control measures including insecticide-treated nets (ITNs) and long lasting insecticidal nets (LLINs). The DDT was banned in 1998; following which, the use of DDT was highly restricted. The malaria again started reappearing. The resurgence of malaria continued (Roll Back Malaria). The current programme is promoting LLINs and ITNs amongst the community as a vector control measure in the epidemic-prone border areas in 34 upazillas which has increased tremendously in last few years. A total of 2.90 million bed nets (LLINS + ITNs) were distributed and 5.79 million people are covered by it. However, its coverage in high-endemic districts ranges from 40 to $63 \%$ (WHO 2010). Approximately $33.6 \%$ of the total population is at risk of malaria. Majority of malaria cases are reported from 13 out of the total 64 districts in the country. About four million populations living in 34 upazillas of eight of the 13 districts live in the epidemic-prone border areas. Focal outbreaks occur every year, and the response to control the epidemic is inadequate. Malaria cases are grossly underreported due to shortcomings in surveillance and information.

\section{DDT stockpiles}

DDT is no more produced in the country and is also not imported. The discontinuation of DDT as well as import of substandard DDT caused obsolete DDT stockpiles in different locations of Bangladesh. The DDT stockpiles of 602.389 MTs comprise 482.904 MTs of substandard DDT at a single location in four MSDs in Chittagong, 101.69 MTs of DDT technical at Bangladesh Chemical Industries Corporation, Chittagong, 12.795 MTs of DDT 75 WP at district godowns of Directorate of Health and 0.005 MTs of

\section{Malaria Cases in Bangladesh}

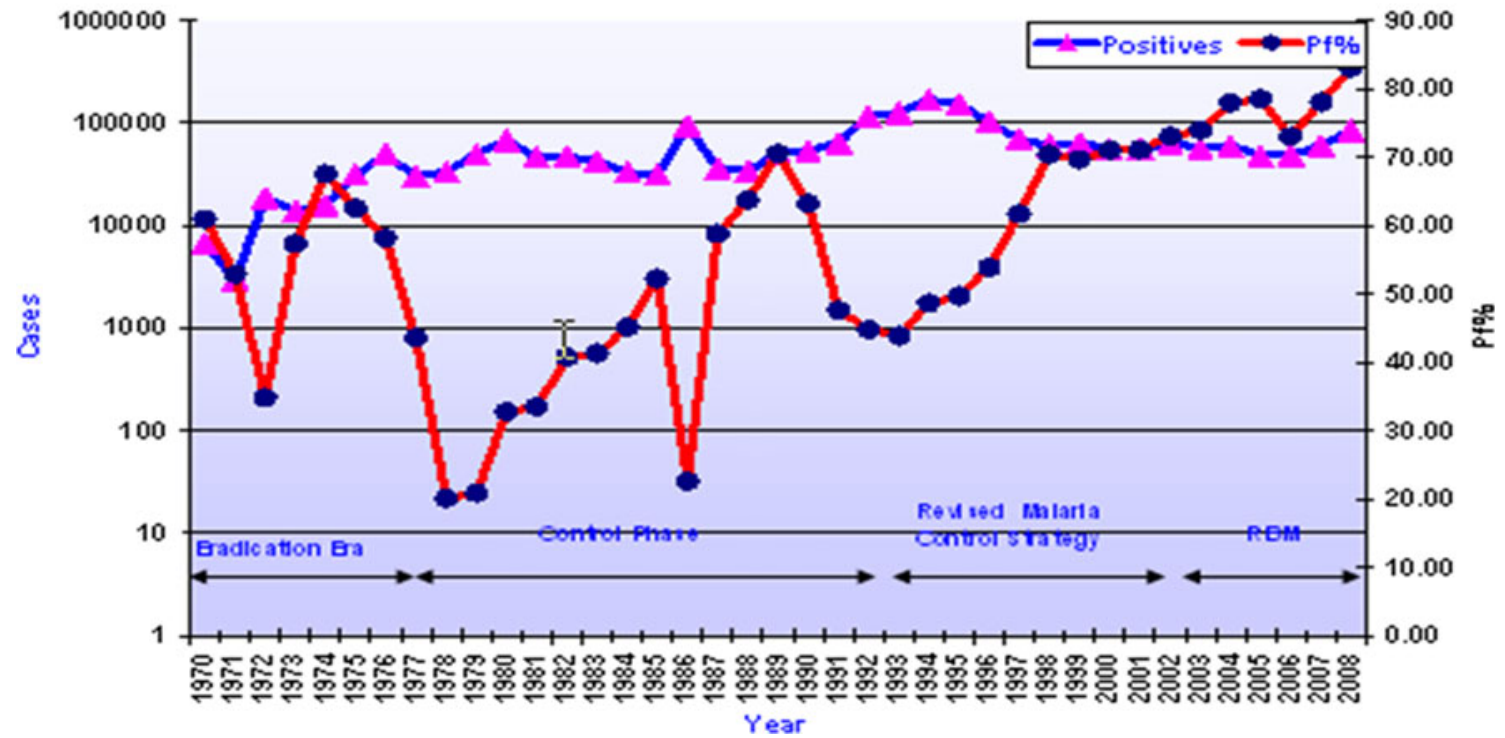

Fig. 1 Confirmed malaria cases during 1970-2008 (WHO 2009) 
DDT $75 \mathrm{WP}$ at district godowns of Department of Agricultural Extension (Rahman 2007). The very poor storage conditions of the MSDs are resulting in seepage, pilferage, weathering and misuse of DDT, which are contaminating the environment. These are suspected, as reported elsewhere (ATSDR 2002), to cause serious health hazards such as cancers and tumours (particularly breast cancer in women), neurobehavioural impairment including learning disorders, endocrine system disruption, reproductive deficits and sexlinked disorders (birth defects/premature birth of baby), a shortened period of lactation in nursing mothers and increased rate of diabetes to the surrounding affected human residents.

Substitutes for DDT for mosquito control and their adverse effects

Currently, peoples are using different insecticidal substitutes for DDT in getting rid of mosquito biting, nuisance, highpitched buzzing, dengue fever, filariasis and malaria. The market survey in Bangladesh reveals that these substitutes include mosquito coils, mats, aerosols and vaporizers prepared with synthetic pyrethroid (SP) and organophosphate insecticides (Table 1). The literature reviews suggest that these substitutes contain along with the active ingredients (AI) other adjuvants and fillers, most of which have adverse effects and may cause several diseases in the affected human beings. Synthetic pyrethroids insecticides are heat stable and used in the treatment of mats, coils and vaporizers, e.g. allethrin and bioallethrin $4 \%, d$-allethrin 0.2 to $0.3 \% \mathrm{w} / \mathrm{w}$, $d$-trans-allethrin 0.1 to $0.15 \% \mathrm{w} / \mathrm{w}, \mathrm{s}$-bioallethrin $1.9 \%$, etc. (Sharma 2001). On heating or burning of mats and liquids, these compounds vaporise without decomposition at temperatures up to $400{ }^{\circ} \mathrm{C}$ and produce repellent action on the mosquitoes. Breathing problems are the most common, and frequently this condition is accompanied with headache or eye irritation or both. Eye irritation is the next common complaint, and often it is accompanied with bronchial irritation, headache or skin reaction, cough, cold and running nose accompanied with fever or sneezing, wheezing and asthma, pain in the ear and throat as the reported adverse effects.

\section{Probable health risks of mosquito coils/mats}

SPs are major AI accounting for about $0.3-0.4 \%$ of coil mass (Lukwa and Chandiwana 1998); the lowest lethal oral dose of which is $750 \mathrm{mg} / \mathrm{kg}$ for children and $1,000 \mathrm{mg} / \mathrm{kg}$ for adults (OHS 1987). Pyrethrins are of low chronic toxicity to humans and low reproductive toxicity in animals, although headache, nausea and dizziness are observed in male sprayers. The remaining components of mosquito coil are organic fillers, binders, dyes and other additives (Weili et al. 2003). Their combustion generates large amounts of submicrometer particles [(particulate matter $<2.5 \mu \mathrm{m}$ in diameter; P[M.sub.2.5])] and gaseous pollutants. Burning one mosquito coil generates $\mathrm{P}$ [M.sub.2.5] = burning 75-137 cigarettes. Coil smoke contains a suite of volatile organic compounds (VOCs), including human carcinogens and suspected carcinogens. Submicrometer particles can reach lower respiratory tract and may be coated with a wide range of organic compounds; some of which are carcinogens or suspected carcinogens (polycyclic aromatic hydrocarbons). Gas phase of coil smoke contains some carbonyl compounds (e.g. formaldehyde and acetaldehyde, as much as $55 \%$ ) with properties that can produce strong irritating effects on upper respiratory tract. The emission of formaldehyde from burning one coil is equal to burning 51 cigarettes. Long-term exposure to coil smoke induces asthma and persistent wheeze in children. Benz $[a]$ anthracene, benzo $[a]$ pyrene, benzo $[b]$ fluoranthene, benzo $[k]$ fluoranthene, dibenz $[a, h]$ anthracene and indeno[1,2,3-ca]pyrene are classified by the US EPA as probable human carcinogens (EPA 1994). Acrolein, glyoxal and methyl-glyoxal known for their high reactivity, strong irritation effects and suspected carcinogenic effects are emitted from coil burning. Several VOCs including benzene, toluene, ethylbenzene, $p, m, o$-xylene and styrene are identified in coil smoke. All are known to cause adverse health effects. Mosquito coils from Asia and South America were reported to generate smoke from heating (or burning) containing submicron particles $(<1 \mu \mathrm{m})$ coated with considerable amount of heavy metals, allethrin and a wide range of vapours such as phenol $o$-cresol, and allethrin used in the mats increased blood-brain barrier (BBB) permeability, suggesting a delayed maturity of BBB (Liu et al. 1987). When mosquito coils containing S-2 (octachlorodipropyl ether) are burned, they release a potent lung carcinogen called bis(chloromethyl) ether (Krieger et al. 2003).

\section{Probable health risks of aerosol}

An aerosol spray often consists of very small droplets of solvent, propellant, and AI. Major AIs of aerosols are SPs. Pyrethrin and pyrethroid illnesses have been reported in many cases (Walters et al. 2009). Most industrial aerosols contain organic solvents, which give off vapours that are dangerous, if breathed for too long or in too high concentrations. Excessive intake can cause headache, giddiness, mental confusion, blurred vision, nausea, weakness and fatigue, numbness of limbs and, in extreme cases, loss of consciousness (GPMU 2008; Harry et al. 1973; ATSDR 2003). Solvents in contact with skin cause irritation and defatting of the skin. Long-term effects of solvent exposure include damage to the heart, liver, kidneys and central nervous system. The most common propellant, butane, is of relatively low toxicity but is extremely flammable. But others are potentially hazardous in addition to flammability. Some of very small droplets of solvent, propellant and AI 
Table 1 Substitutes for DDT and their formulations in Bangladesh market and their hazard classifications

\begin{tabular}{|c|c|c|c|c|}
\hline Sample \# & Active ingredient $/$ class $^{\mathrm{a}}$ & Formulation type/product types ${ }^{\mathrm{a}}$ & WHO class & Health risks \\
\hline 01 & Allethrin (SP) & Mat, Aerosol & III & a \\
\hline 02 & $d$-allethrin (SP) & Mat, Coil & II & $\mathrm{b}$ \\
\hline 03 & $d$-allethrin (Pynamine Fort) (SP) & Coil & II & $\mathrm{b}$ \\
\hline 04 & $d$-trans-allethrin (SP) & Coil & II & $\mathrm{b}$ \\
\hline 05 & Alpha Cypermethrin (SP) & WP, EC, SC & II & No evidence \\
\hline 06 & Bioallethrin (SP) & Aerosol & II & $\mathrm{a}$ \\
\hline 07 & S-Bio-allethrin (SP) & Coil & II & $\mathrm{b}$ \\
\hline 08 & Chlorpyriphos (OP) & EC & II & No evidence \\
\hline 09 & Cypermethrin (SP) & EC & II & No evidence \\
\hline 10 & Deltamethrin (SP) & Chalk, EC, SC, WP, Flow, DP & II & No evidence \\
\hline 11 & Diazinon (OP) & EC & II & No evidence \\
\hline 12 & ETOC (Prallethrin) (SP) & Mat, Coil, Vaporizer & II & $\mathrm{b}$ \\
\hline 13 & Fenthion (OP) & EC & II & No evidence \\
\hline 14 & Fenitrothion (OP) & EC & II & No evidence \\
\hline 15 & Imiprothin (SP) & Aerosol & III & $\mathrm{a}$ \\
\hline 16 & Lambda Cyhalothrin (SP) & WP, EC & II & No evidence \\
\hline 17 & Malathion (OP) & EC & III & No evidence \\
\hline 18 & Metofluthrin (SP) & Coil & & $\mathrm{b}$ \\
\hline 19 & Permethrin (SP) & Aerosol, Powder, EC, WP, DP & II & No evidence \\
\hline 20 & Phenthoate (OP) & Liquid, EC & II & No evidence \\
\hline 21 & Pirimiphos Methyl (OP) & $\mathrm{EC}$ & III & No evidence \\
\hline 22 & Pynamine Fort (SP) & Liquid vaporizer & III & $\mathrm{a}$ \\
\hline 23 & Prallethrin (SP) & Aerosol, Coil, Mat, Vaporizer & II & $\mathrm{b}$ \\
\hline 24 & Propoxur (Car) & Aerosol & II & $\mathrm{a}$ \\
\hline 25 & Sumione (SP) & Coil & II & $\mathrm{b}$ \\
\hline 26 & Temephos (OP) & $\mathrm{EC}, \mathrm{G}$ & $\mathrm{U}$ & No evidence \\
\hline 27 & Tetramethrin (SP) & RS, Aerosol & $\mathrm{U}$ & $\mathrm{a}$ \\
\hline 28 & D-Tetramethrin (SP) & Aerosol & $\mathrm{U}$ & $\mathrm{a}$ \\
\hline 29 & Transfluthrin (SP) & Coil & $\mathrm{U}$ & $\mathrm{b}$ \\
\hline
\end{tabular}

WHO class II means moderately hazardous (non-carcinogenic, non-teratogenic, etc.). WHO class III means slightly hazardous. WHO class U means unclassified. "No evidence" means literatures searched did not indicate significant health hazards under proper use. Letter "a" means health hazards are probable through high concentrations and long exposure due to organic solvents and propellant other than butane. Letter "b" means health hazards are most probable through emissions due to ingredients other than active ingredients

$S P$ synthetic pyrethroid, $O P$ organophosphate, Car carbamate

${ }^{a}$ Sample market survey and registry record

are ideally suited for breathing deep into lungs. Larger droplets are trapped in the nose, throat and upper part of the lungs.

\section{Probable health risks of vaporiser}

AIs of most vaporisers are SPs. By applying the electrovaporizer "Nexa Lotte" plug-in mosquito killer, concentrations for $d$-allethrin were in the range of 5-12 and 0.5$2 \mu \mathrm{g} / \mathrm{m}^{3}$ for PBO, while with the "Paral" plug-in mosquito killer, concentrations of $0.4-5 \mu \mathrm{g} / \mathrm{m}^{3}$ for pyrethrins and $1-$ $7 \mu \mathrm{g} / \mathrm{m}^{3}$ for PBO were measured (Berger-Preiss et al. 2009).
Human biomonitoring data revealed urine concentrations of the metabolite $(E)$-trans-chrysanthemum dicarboxylic acid ((E)-trans-CDCA) between 1.7 and $7.1 \mu \mathrm{g} / \mathrm{l}$ after $5 \mathrm{~min}$ of exposure to the different sprays. Also, the use of electro-vaporizers led to $(E)$-trans-CDCA concentrations in the urine in the range of 1.0 to $6.2 \mu \mathrm{g} / 1(1-3 \mathrm{~h}$ exposure period).

Alternative safe way of mosquito management

In the above context, the wise alternative to DDT for mosquito/malaria control may only refer to adoption of 
the integrated vector (mosquito) management (IVM) (William and Julie 1998; Sharma 2001; WHO 2004). IVM entails the use of a range of interventions of proven efficacy, separately or in combination, in order to implement more costeffective control and reduce reliance on any single intervention. This strategy also serves to extend the useful life of insecticides and drugs by reducing the selection pressure for resistance development (WHO 2004). To prevent breeding of mosquitoes, IVM may include removal/cleaning of all breeding sites, e.g. bird baths, rain barrels, old automobile tires, ditches, unused swimming/water pools, tree holes, flower pots and roof gutters to avoid stagnant water/breeding of mosquitoes. To control larvae, the most logical approach includes examining each week the presence of larvae, using one or more of the insecticides such as Bacillus thuringiensis Berliner var. israelensis, methoprene- an insect growth regulator (Altosid or any available formulation) to second, third and fourth instars larvae in water, petroleum distillate oil and temephos. To control adults, the use of adulticides such as ultra-low volume application (malathion/chlorpyrifos/chlorpyrifos + permethrin), thermal fogging with malathion/chlorpyrifos/chlorpyrifos + permethrin as a space treatment against adult mosquitoes at night or early morning when the air is calm (less than $5 \mathrm{mph}$ ) or applying insecticide residual spray as barrier treatments to tall grasses, weeds, shrubs, fences and other harborages surrounding parks, playgrounds and residences to help reduce adult mosquito populations, and in endemic areas following WHO recommendation (CDC 2011) to avoid contact of adult mosquitoes using LLINs/ITNs.

\section{Conclusions and recommendation}

From the above findings, it is concluded that any sole chemical substitute for DDT is health hazardous and the better alternative comprise the use of IVM package comprising microbial, physical, habitat sanitation and safer chemical methods including use of LLINs/ITNs. Therefore, wise recommendations to manage mosquitoes to prevent malaria should be adopted to replace DDT with IVM and not by any other single method, which may cause health and environmental hazards as much as caused by DDT.

Open Access This article is distributed under the terms of the Creative Commons Attribution License which permits any use, distribution, and reproduction in any medium, provided the original author(s) and the source are credited.

\section{References}

ATSDR (Agency for Toxic Substances and Disease Registry) (2002) Toxicological profile for DDT, DDE, and DDD. Update. U.S.
Department of Health and Human Services, Public Health Service, Atlanta

ATSDR (Agency for Toxic Substances and Disease Registry) (2003) Public health statement for pyrethrins and pyrethroids. U.S. Department of Health and Human Services, Public Health Service, Atlanta

Banglapedia (National Encyclopedia of Bangladesh) (2006) Malaria. Available at http://www.banglapedia.org/httpdocs/HT/M 0102.HTM

Berger-Preiss E, Koch W, Gerling S, Kock H, Appel KE (2009) Use of biocidal products (insect sprays and electro-vaporizer) in indoor areas-exposure scenarios and exposure modeling. Fraunhofer Institute for Toxicology and Experimental Medicine, Nikolai-Fuchs-Str. 1, 30625 Hannover, Germany. edith.bergerpreiss@item.fraunhofer.de

CDC (2011) Malaria. Insecticide-treated bed nets. Available at http:// www.cdc.gov/malaria/malaria_worldwide/reduction/itn.html

EPA (1994) Environmental Criteria and Assessment Office and Office of Health and Environmental Assessment. Integrated Risk Information System (IRIS). U.S. Environmental Protection Agency, Cincinnati

GPMU (2008) Aerosol spray products. GPMU safety reps handbook. Unite, Unite House, 128 Theobald's Road, Holborn, London, WC1X 8TN. Available at http://www.unitetheunion.org/pdf/ 27Aerosolsprayproducts.pdf

Harry JE, Charles IF, Lawrence WO, Marvin IT (1973) Aerosol research and development related to health hazard analysis. Aerosol Studies Section. Industrial Hygiene Group. National Institute for Occupational Safety and Health, Cincinnati, Ohio. Project R072. USA

Krieger RI, Dinoff TM, Zhang X (2003) Octachlorodipropyl ether (S-2) mosquito coils are inadequately studied for residential use in Asia and illegal in the United States. Environ Health Perspect 111:1439 1442. doi:10.1289/ehp.6177

Liu WK, Wong MS, Mui YL (1987) Toxic effects of mosquito coil (a mosquito repellant) smoke on rats: I. Properties of the mosquito coil and its smoke. Toxicol Lett 39:223-230

Lukwa N, Chandiwana SK (1998) Efficacy of mosquito coils containing $0.3 \%$ and $0.4 \%$ pyrstherins against $A n$. gambiae sensu lato mosquitoes. Cent Afr J Med 44(4):104-107

OHS (1987) Pyrethrum, material safety data sheet. Occupational Health Services, Inc., New York

Rahman MM (2007) Mirroring obsolete pesticides issues of Bangladesh through international standards. In: Vijgen J, Plesca V, Barbarasa I, Cupecea L (eds) Forum Book on the 9th International $\mathrm{HCH}$ and Pesticides Forum for Central and Eastern European, Caucasus and Central Asian Countries held during 20-22 September, 2007 at Chisinau, Republic of Moldova, Europe. Available at http://www.hchforum.com/presentations/pdf/III-21_ Rahman_Mahbubar.pdf

Sharma VP (2001) Health hazards of mosquito repellents and safe alternatives. Curr Sci 80:341-343

Walters JK, Boswell LE, Green MK, Heumann MA, Karam LE, Morrissey BF, Waltz JE (2009) Pyrethrin and pyrethroid illnesses in the Pacific Northwest: a five-year review. Public Health Reports/January-February 2009/Volume 124. (C2009 Association of Schools of Public Health. Oregon Department of Human Services, Public Health Division, Toxicology, Assessment, \& Tracking Services, 800 NE Oregon St., Ste. 640, Portland, OR 97232

Weili L, Junfeng Z, Jamal H, Jalaludin, Zailina H, Bernard DG (2003) Mosquito coil emissions and health implications - research. Environ Health Perspect 111:1454-1460. doi:10.1289/ehp.6286. Available via http://www.dx.doi.org/ [Online 30 April 2003]

WHO (WHO South East Asia Regional Office) (2009) The revised malaria control strategy. 2006-2010 
WHO (WHO South East Asia Regional Office) (2010) Malaria situation in SEAR countries, Bangladesh. WHO/SEAR Report 2010. Available at www.searo.who.int/en/Section10/Section21/Section340_4015.htm

WHO (World Health Organization) (2004) Global strategic framework for integrated vector management. Available at http://whqlibdoc. who.int/hq/2004/WHO_CDS_CPE_PVC_2004_10.pdf
William FL, Julie AS (1998) Mosquito pest management. The Ohio State University Extension Bulletin. Ohio State University Extension Entomology Building, 1991 Kenny Road, Columbus, Ohio 43210-1090, E-mail: Extento@postoffice.ag. ohio-state.edu. Available at http://www.ohioline.osu.edu/b641/ index.html 